\title{
Product platform architecture for cloud manufacturing
}

\author{
Wei Wei ${ }^{1}$ (D) Feng Zhou $^{1} \cdot$ Peng-Fei Liang ${ }^{1}$
}

Received: 25 May 2019/Revised: 9 December 2019/Accepted: 8 April 2020/Published online: 15 May 2020

(C) The Author(s) 2020

\begin{abstract}
Cloud manufacturing is emerging as a new manufacturing paradigm and an integrated technology. To adapt to the increasing challenges of the traditional manufacturing industry transforming toward service-oriented and innovative manufacturing, this paper proposes a product platform architecture based on cloud manufacturing. Firstly, a framework for the product platform for cloud manufacturing was built. The proposed architecture is composed of five layers: resource, cloud technology, cloud service, application, and user layers. Then, several key enabling technologies for forming the product platform were studied. Finally, the product platform for cloud manufacturing built by a company was taken as an application example to illustrate the architecture and functions of the system. The validity and superiority of the architecture were verified.
\end{abstract}

Keywords Cloud manufacturing · Cloud service $\cdot$ Product platform $\cdot$ Architecture $\cdot$ Product collaborative design

\section{Introduction}

Cloud computing provides three types of services: software as a service (SaaS), platform as a service (PaaS), and infrastructure as a service (IaaS). Cloud manufacturing [1] is a new manufacturing model developed from the concept of "manufacturing as a service (MaaS)" derived from networks such as the internet and internet of things (IoT),

Wei Wei

weiwei@buaa.edu.cn

1 School of Mechanical Engineering and Automation, Beihang University, Beijing 100191, People's Republic of China telecommunication networks, broadcast and television networks, and wireless broadband networks based on the above three service models. Cloud manufacturing integrates and develops existing manufacturing information technologies (such as computer-aided design, production, experiment, simulation, management, and integration) and emerging information technologies (such as cloud computing, IoT, service computing, intelligent science, and high-efficiency computing).

Various types of manufacturing resources and capabilities are virtualized and made service-oriented to form a service cloud pool that can be unified and centralized for optimization management. The core of cloud manufacturing is to share manufacturing resources and capabilities. The key to cloud manufacturing is to build a public product platform for cloud manufacturing to realize the unified management of manufacturing resources and capabilities that can be accessed on demand by users through the cloud anywhere and anytime. Therefore, the efficient sharing and utilization of resources is realized, and the lifecycle of manufacturing is intelligently completed [2].

The product platform for cloud manufacturing is a complex system. Therefore, construction of the platform needs key enabling technologies to solve problems and maintain the efficiency and sustainability of the system. Golightly et al. [3] discussed the technology of collaboration in cloud manufacturing environments. The IoT, cloud computing, and high-performance computing technologies are the current emerging information technologies that are integrated and developed with cloud manufacturing $[4,5]$. Cloud manufacturing still needs technologies that can directly interact with machine tools and other physical devices. In recent years, with the development of computer technology, users have had increasingly higher requirement for interactive interfaces. Therefore, technologies for the 
user terminal to utilize cloud services are also very important for cloud manufacturing (e.g., intelligent user interface [6] and human-computer interaction [7]).

In the research on cloud manufacturing, MIT conducted a DICE research project and developed a product design system based on cloud manufacturing to provide a shared working space for designers so they could participate in any part of the design process [8]. Stanford University conducted the SHARE project, where team members shared design knowledge and ideas through the cloud [9]. The Boeing Company, the largest aircraft manufacturer in the world, adopted internet-based collaborative design to manage manufacturing companies in more than 40 countries and regions around the world and collaboratively build Boeing 787 passenger aircraft. This approach shortened the development cycle by $30 \%$ and reduced costs by $50 \%$ [10].

The team, led by Bo-hu Li, an academician at the Chinese Academy of Engineering, conducted research on cloud design and simulation and built a cloud simulation platform that was applied to the collaborative design of aircraft virtual prototypes [11]. The research results of Katzmaier and Hanneghan [12] demonstrated that the internet-based design pattern had overtaken the original design pattern in terms of versatility, diversity, and synergy.

Cloud manufacturing not only takes advantage of the operating model of cloud computing but also inherits the advantages of advanced manufacturing models such as networked and flexible manufacturing [13]. A comparison between cloud manufacturing and other advanced manufacturing models is shown in Table 1 . The efficient sharing of large manufacturing resources, good system availability, and high user participation make the cloud manufacturing model a pivotal innovation in advanced manufacturing models [14].
A product platform for cloud manufacturing can break through the limitations of the boundaries and resources of a company and make users transparently access rich resources. The platform provides a support environment for efficiently sharing the resources of product design and can improve the utilization of manufacturing resources and shorten the product development cycle. In addition, the platform will be of great significance in improving the competitiveness of the product market and accelerating the transformation of manufacturing from product oriented to service oriented.

In this research, a product platform model based on cloud manufacturing is proposed. To better adapt to the increasing challenges of the traditional manufacturing industry transforming toward service-oriented and innovative manufacturing, this paper proposes an architecture of the product platform for cloud manufacturing and advanced manufacturing technologies that contribute to the evolution of the cloud-based product platform. Moreover, a product platform for cloud manufacturing built by a company is adopted as an example to illustrate the architecture and functions of the system. The validity and superiority of the architecture are verified.

\section{Architecture of product platform for cloud manufacturing}

At present, improving the design efficiency of complex products, ensuring product design quality, reducing product design cost, and satisfying the diversified needs of users are important considerations for the survival and development of companies [15].

Product design is the key to product quality and manufacturing costs. The developing model based on the product platform can make use of high-precision equipment, senior experts, design knowledge, and other resources, and can

Table 1 Comparison of characteristics of three advanced manufacturing models

\begin{tabular}{|c|c|c|c|}
\hline & Flexible manufacturing & Network manufacturing & Cloud manufacturing \\
\hline System functions & Cooperation & Resource sharing/cooperation & $\begin{array}{l}\text { Resource sharing/resource } \\
\text { efficiency/cooperation }\end{array}$ \\
\hline System openness & Many constraints, poor openness & Better openness & Highly open \\
\hline Resource type & $\begin{array}{l}\text { Organization, human, } \\
\text { technology } \cdots\end{array}$ & $\begin{array}{l}\text { Equipment, people, } \\
\text { materials, network, } \\
\text { information } \cdots\end{array}$ & $\begin{array}{l}\text { Materials, equipment, software, } \\
\text { hardware, logistics, human, knowledge } \cdots\end{array}$ \\
\hline Data amount & GB level $\left(1 \mathrm{~GB}=10^{9} \mathrm{~B}\right)$ & TB level $\left(1 \mathrm{~TB}=10^{12} \mathrm{~B}\right)$ & PB level $\left(1 \mathrm{~PB}=10^{15} \mathrm{~B}\right)$ \\
\hline Resource usage & Customization & Dynamic configuration & On-demand dynamic configuration \\
\hline User participation & Moderate & Moderate & High \\
\hline Collaboration scope & Several companies & Companies in several industries & Companies in almost every industry \\
\hline Key technologies & $\mathrm{FMT} / \mathrm{CAD} / \mathrm{AI}$ & Service/ASP/Globus & Service/Cloud computing/Internet of Things \\
\hline
\end{tabular}


also organize and manage these resources effectively to improve the utilization of resources [16].

Although the system environment constructed by a traditional distributed network can complete collaborative work, the demand of the user for system dynamics cannot be satisfied owing to the restrictions of the static nature of software and hardware systems [17]. The fundamental feature of a cloud manufacturing service system is eliminating the information island of manufacturing resources for the efficient sharing and on-demand allocation of resources. A network environment with dynamic adaptability and expansibility constructed by the cloud manufacturing system can fully share resources and reduce costs.

The traditional product platform architecture is divided into resource, tool, and application layers. The traditional manufacturing model focuses on pooling resources and completing product development tasks as independently as possible. In essence, the product development process is completed by multiparty cooperation, and the computing resources are significant. The actual application requirements have not been met by traditional product platforms. Therefore, a model based on the product platform and cloud manufacturing technology was developed, and a product platform architecture for cloud manufacturing was proposed.

The framework structure of a product platform for cloud manufacturing is shown in Fig. 1. The product platform for cloud manufacturing, which supports business collaboration between distributed enterprises, is fused and expanded based on its original architecture. It can efficiently share standardized design, manufacturing, information, and technology resources related to product development and optimize their utilization.

\subsection{Resource layer}

The resource layer is the physical foundation of the product platform for cloud manufacturing [18]. The resources in the platform mainly refer to the collection of software, hardware, computing power, knowledge, and standards involved in the entire lifecycle of the product. In the cloud manufacturing environment, users select and utilize resources that are beneficial to complete tasks among a wealth of resources. In the traditional networked manufacturing model, to effectively evaluate and control the execution of collaborative processes, users need to have certain network knowledge to understand the topology and layout of resources.

For a cloud manufacturing environment with massive resources, the system dynamically and intelligently allocates related resources to users. Therefore, the cloud manufacturing environment reduces requirements of the network knowledge of participants and the imbalance of resources (overload or idle), and improves resource utilization.

\subsection{Cloud technology layer}

In the product platform for cloud manufacturing, the key to achieving collaboration is to solve the resource-sharing problem in the cloud manufacturing environment. Crosssector, cross-enterprise, and even cross-regional resource

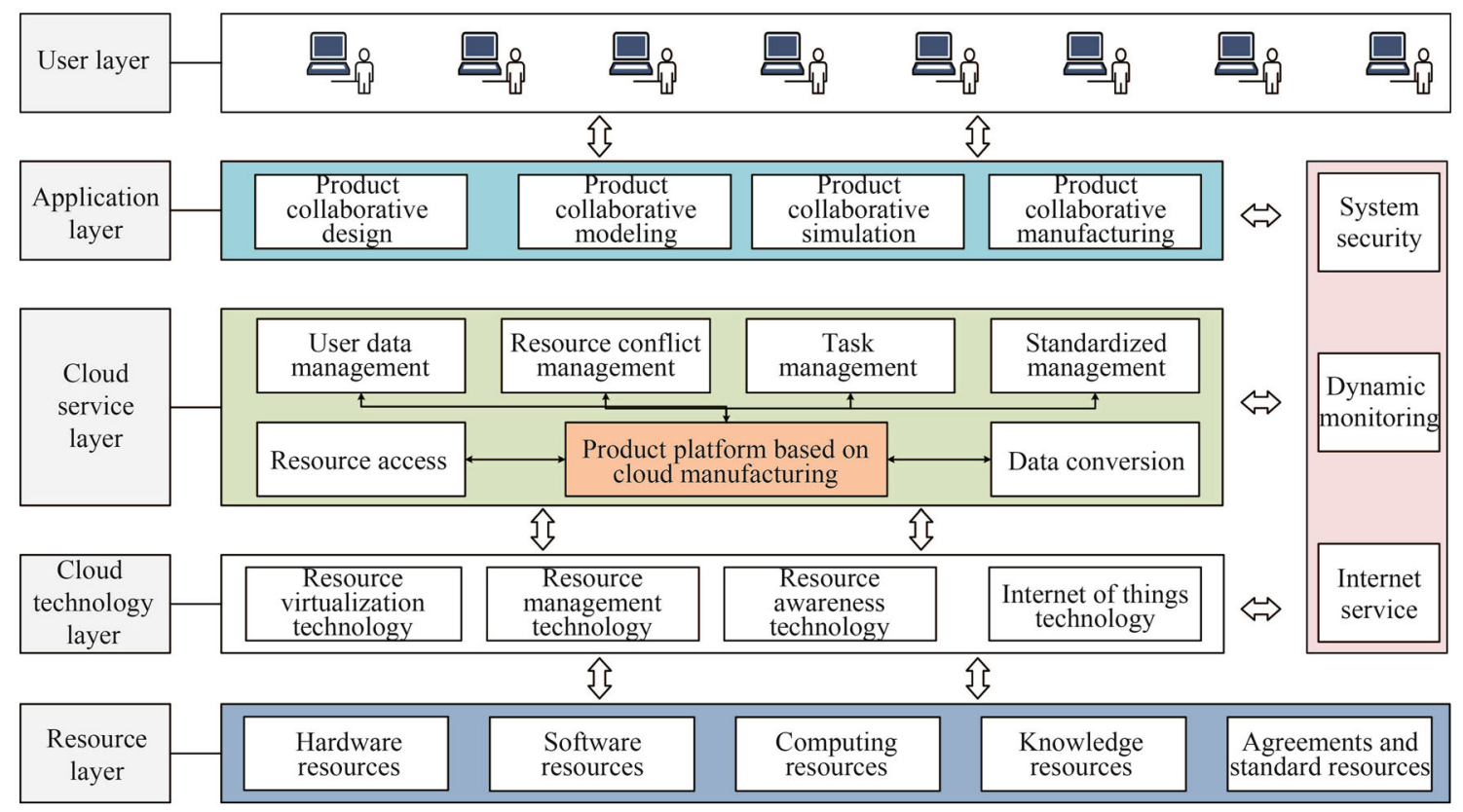

Fig. 1 Architecture of product platform based on cloud manufacturing 
sharing can avoid repeating utilization of resources, increase resource utilization, and reduce product cost. The resources have features such as diversity, heterogeneity, and particularity. To effectively share these resources, the first issue that needs to be solved is the description of these design resources for unified standards and encapsulation.

The purpose of the cloud technology layer is to shield the heterogeneity and complexity of resources, access the cloud manufacturing service platform, and provide a unified interface to realize the efficient sharing and collaboration of resources. Various approaches can shield the heterogeneity and complexity of resources, including resource virtualization, resource management, resource awareness, and IoT technologies.

(i) Resource virtualization technology. The core technology of cloud manufacturing is resource virtualization technology. This can realize the comprehensive interconnection, sensing, and feedback control of manufacturing resources, and transform manufacturing resources into logical manufacturing resources to support the virtual cloud manufacturing service environment with a high level of resource utilization, agility, reliability, security, and availability [19].

(ii) Resource management technology. In the product collaborative design system of cloud manufacturing services, resource management technology can realize the discovery and rapid sharing of massive resources in the cloud, and fully monitor the service status of resources to ensure the smooth and efficient operation of manufacturing services [20].

(iii) Resource awareness technology and IoT technology. In a cloud manufacturing system, various manufacturing resources and capabilities can be intelligently sensed and connected into the wider internet, and automatically managed and controlled using resource awareness technology and IoT technologies (e.g., radio frequency identification (RFID), wired and wireless sensor networks, and embedded systems) [21].

\subsection{Cloud service layer}

The cloud service layer is critical to the operation of the product platform for cloud manufacturing. It mainly includes services such as user data management, standardized management, task allocation, conflict resolution, and system security.

(i) User data management service. In the collaborative work process, the user data management service automatically adds or deletes users according to the task execution requirement, and records the users' task execution history to ensure the efficient and orderly execution of the tasks.

(ii) Standardized management services. Standardized management is the prerequisite to providing efficient services with resources. The establishment of unified standards for different resources can facilitate the registration and invocation of resources and reduce the response time of resource services. The establishment of evaluation standards for service quality and the monitoring of changes in service quality can eliminate disqualified resources and ensure that the platform can provide high-quality design services.

(iii) Task assignment service. Task assignment is critical for collaboration. The product platform for cloud manufacturing intelligently decomposes complex tasks and allocates tasks according to the capabilities of service resources.

(iv) Conflict resolution service. Collaboration is the process of continuous conflict generation and elimination. For example, resources that are accessed by different users will inevitably create conflicts in time. The method of effectively eliminating conflicts and ensuring the efficiency of resource access is an important issue that needs to be considered.

(v) System security service. The security of the system is a prerequisite for normal operation, including user information security, design data security, and access process security.

\subsection{Application layer}

The application layer is the most intuitive presentation layer of the product platform for cloud manufacturing. It implements functions by establishing corresponding interfaces. Users can also combine and reconfigure existing functions to meet the needs of collaborative tasks. This study introduces product collaborative design, modeling, simulation, and manufacturing. Specific functions will be introduced in detail in Sect. 4.

\subsection{User layer}

The user layer is the portal layer of the product platform. The user layer provides the user with a working environment through the network so that users can access the product platform anytime and anywhere. Users can perform resource access, service invocation, task submission, and task monitoring based on the task needs. In addition, 
users can query information such as the service history of the resources and select the most suitable resource to minimize the cost. In recent years, with the development of computer technology, users have had higher and higher requirements for interactive interfaces. Therefore, a good interactive interface is also very important for the product platform for cloud manufacturing.

\section{Key technologies of product platform for cloud manufacturing}

The product platform for cloud manufacturing is a complex system. Therefore, the construction of the platform needs to be based on technologies such as cloud manufacturing, product family and product platforms, and product collaborative design. The specific details are shown in Fig. 2. The key technologies that are more important are described below.

\subsection{Key technologies of cloud manufacturing}

\subsubsection{IoT technology}

IoT technology is one of the key technologies for cloud manufacturing. There are three levels of application of IoT technology in cloud manufacturing [22]. (i) The IoT is used to realize the perception of various manufacturing equipments, internet connections, acquisitions, and automatic control. (ii) The IoT is used to make logistics and energy in intelligent manufacturing systems as well, and support the intelligent operator of services such as intelligent interaction and collaboration between services. (iii) The users of cloud manufacturing are mainly internet users, and IoT technology can support the communications of these users.

\subsubsection{Cloud service technology}

Cloud service technology is the core technology of the product platform for cloud manufacturing. Cloud service technology uses technologies such as the IoT and virtualization to encapsulate distributed cloud resources and capabilities based on knowledge. This involves the fusion of structured experience, value, relevant information, and expert insight through the entire life cycle of manufacturing (such as manufacturing domain knowledge, design knowledge, rule knowledge, process knowledge, and model knowledge), and then accesses cloud platform.

Manufacturing resources and capabilities, primarily referring to software, hardware, computing power, knowledge, and standards involved in the entire life cycle of the product, are highly virtualized into cloud services and provide users with manufacturing lifecycle applications in the form of services. The process of cloud service formation is the process of cloud manufacturing resources and capabilities being serviced [17]. The relationship of resources, manufacturing cloud, and cloud services in the cloud manufacturing system is reflected in Fig. 3.

In cloud manufacturing services, besides the computational resources (such as the server, storage, network, and software [20]) involved in cloud computing, all manufacturing resources and capabilities are provided for the user

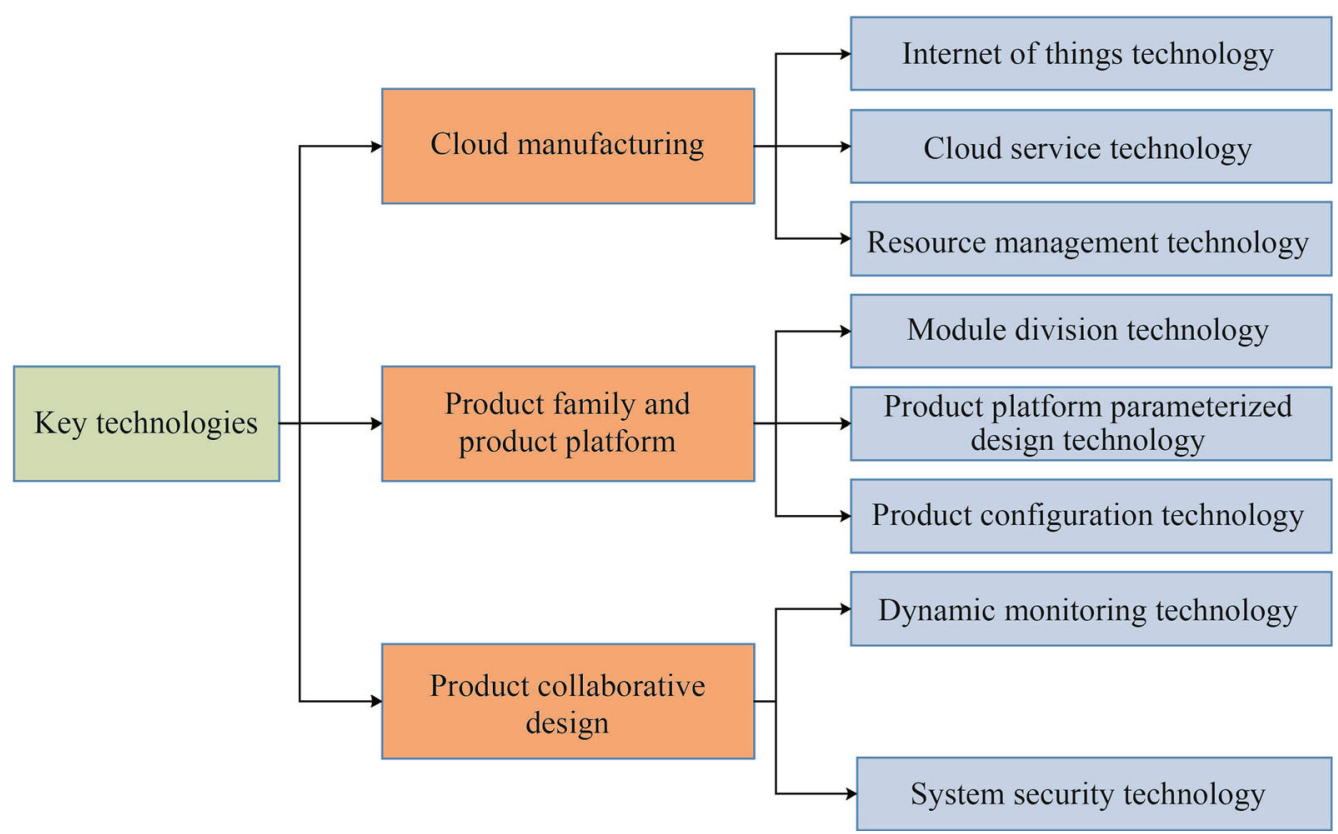

Fig. 2 Key technologies of the product platform for cloud manufacturing 
in different service models based on IaaS, PaaS, and SaaS, including the following models: argumentation as a service, design as a service, fabrication as a service, experiment as a service, simulation as a service, and integration as a service [16].

The computing resources in cloud manufacturing resources are similar to those in cloud computing. The difference is that cloud manufacturing resources are not limited to computing resources but extend to a wider range of resources including manufacturing equipment resources. The difference and relationships between cloud computing and cloud manufacturing are illustrated in Fig. 4 [20].

\subsubsection{Resource management technology}

Resource management technology is a key and difficult point for the realization of the product platform for cloud manufacturing. The cloud manufacturing system is an environment that integrates manufacturing resources and capabilities, including many heterogeneous and off-site resources. Effectively managing these resources is a major challenge for the system. Therefore, resource management technology needs to involve the following aspects.

(i) Unified classification and description of resources. Distribution, heterogeneity, autonomy, and quantity are the characteristics of manufacturing resources in a cloud manufacturing service environment. Various types of resources that may be used in the cloud manufacturing process need to be uniformly classified and described to facilitate the integration, sharing, and management of manufacturing resources in this environment. For various resources and tasks of cloud

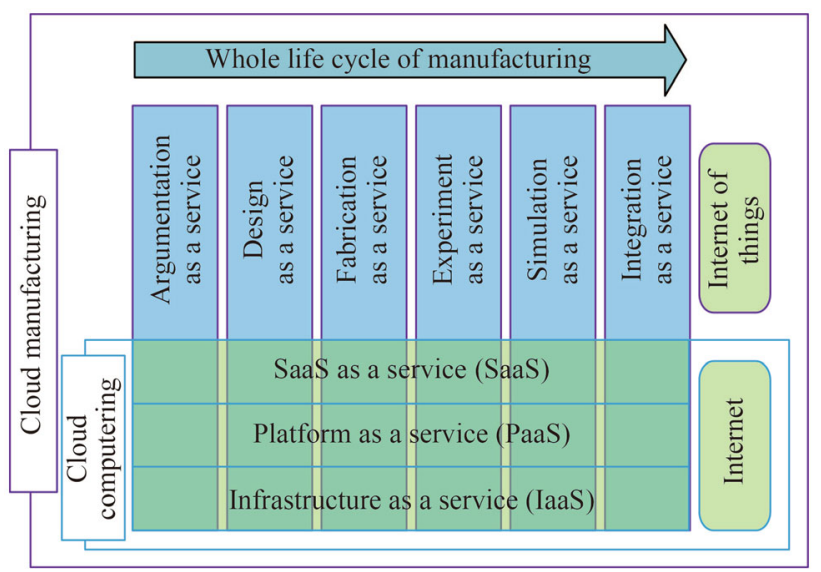

Fig. 4 Relationship between cloud computing and cloud manufacturing

manufacturing, the extensible markup language (XML), web service ontology language (OWL-S), and unified modeling language (UML) can be used in the data layer, semantic layer, and logical layer, respectively, to establish corresponding extensible description templates [23-25].

Figures 5 and 6 present an example of the manufacturing equipment. The description is implemented in the XML language, which is popular for data exchange and interoperable web applications. In addition, in the process of establishing the description of manufacturing resources, the requirements of resource discovery, integration, and matching need to be fully considered, and the resources need to be described as completely as possible.

Figure 5 shows the XML schema of the

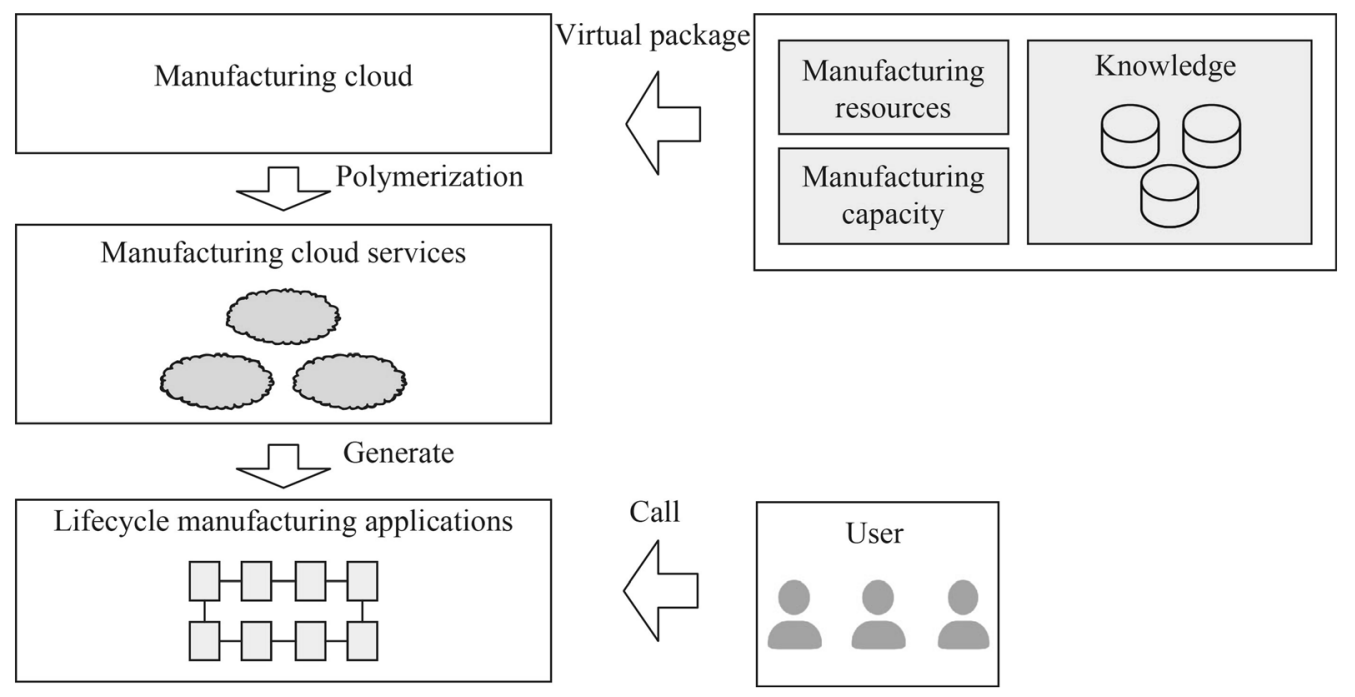

Fig. 3 Relationship of resources, cloud services and manufacturing clouds in cloud manufacturing system 
manufacturing equipment. The ProfileInfo that appears in Fig. 5 describes the basic information, and the ManageInfo describes the utilization of this manufacturing equipment. The schema can be extended or customized when they are applied to other kinds of manufacturing resources. Figure 6 shows the XML document of a machine. The content of the document is generated by a cell view that reflects the manufacturing resource description of the machine.

(ii) Virtualization of resources. Resources need to be virtualized before they are deployed to cloud manufacturing systems. Virtualization of resources can shield the off-site distribution and heterogeneity of resources so that they can achieve unified access on the network [19]. The key to the virtualization of resources is to transform the heterogeneous manufacturing resources into homogeneous cloud services.

Resource virtualization can be implemented in two phases: virtual description and service encapsulation. Virtual description aims to build a resource description specification that represents the manufacturing resource information comprehensively in a unified virtual resource data model. Service encapsulation extracts functional features of manufacturing resources from the virtual resource data model and encapsulates them as cloud services to interoperate with the cloud platform in a uniform interface. The resource descriptions are encapsulated by a standard

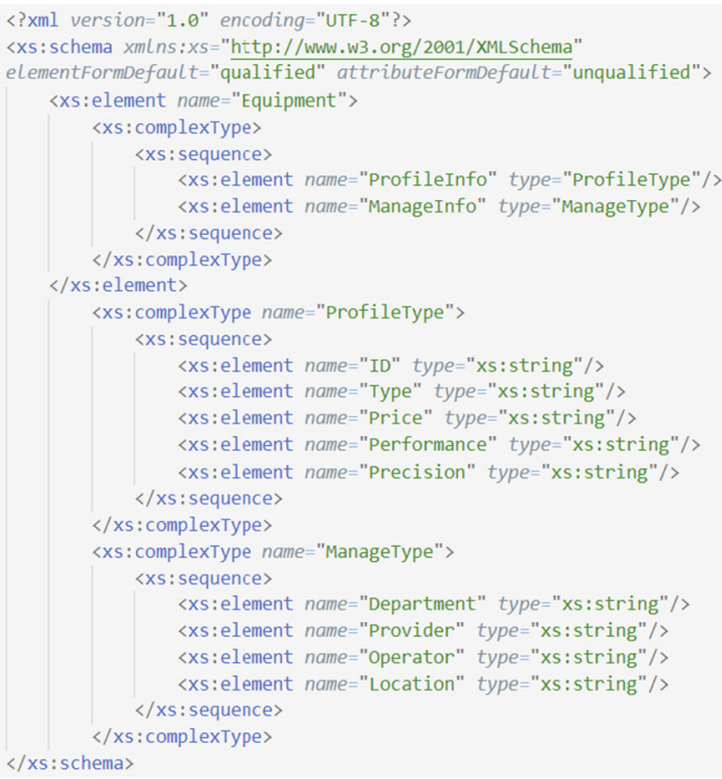

Fig. 5 Schema of the manufacturing equipment

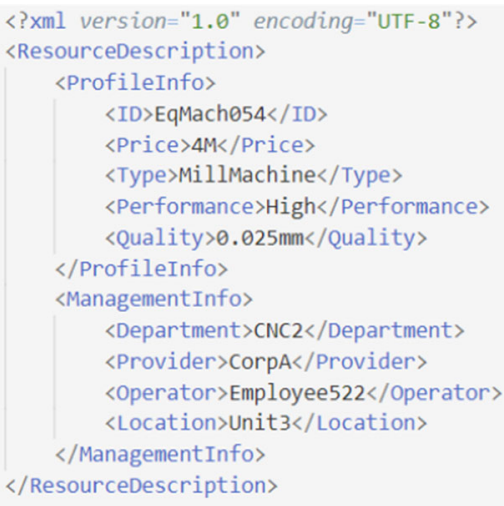

Fig. $6 \mathrm{XML}$ document of the equipment

encapsulation operation using a cloud service template [26].

(iii) Resource discovery. For the massive resources in the product platform for cloud manufacturing, the rapid sharing of resources must be achieved through a good discovery mechanism so that users can easily search for the required service resources. Therefore, research on an efficient resource search algorithm and a historical taskbased resource discovery model is important for solving the problem.

(iv) Resource binding strategy. The dynamic binding of resources intelligently matches and binds the services with corresponding resources and monitors the service status of resources throughout the process to ensure the smooth and efficient operation of manufacturing services.

\subsection{Key technologies of product platform}

\subsubsection{Module division technology}

The module division technology is mainly used in the following two aspects in the product platform for cloud manufacturing. Firstly, through the analysis of different functions and specifications of product units, a series of functional modules is constructed and designed, and then different products can be formed through the selection and combination of modules to meet the various needs of the market [27]. Secondly, complex tasks are quickly divided into several schedulable subtasks. Then, a mapping relationship between completing tasks in the cloud manufacturing environment is created. Finally, each subtask user is coordinated to complete this task [28]. In the task division process, the following principles should be followed: task decomposability, moderate granularity, task independence, time additivity, and cost additivity. 


\subsubsection{Product platform parameterized design technology}

Parameterized design technology is a typical technology of the product platform. Firstly, the parameterized design data received from the user interaction interface are processed, and the parameters driven for the structural model are generated according to the parameter transfer relationship. Then, the newly generated module parameters are entered into the corresponding model database to modify a new product's 3D model and 2D drawings.

\subsubsection{Product configuration technology}

The product configuration system for cloud manufacturing resources consists of five main modules to enable product configuration: visualization and configuration engines, product assessment, user interface and cloud manufacturing servers [29]. The relationship between product configuration and manufacturing cloud services is shown in Fig. 7.

The manufacturing cloud service supports the product configuration. After responding to the system request, the manufacturing cloud service sends the required productrelated data to the system. When the product configuration is completed, the final product specification and related information can be submitted for further processing.

The purpose of the configuration engine is to generate valid product specifications based on user input requirements, with reference to mandatory configuration rules and constraints. The visualization engine provides dynamic web-based product visualization to view and manipulate 3D product models to support product configuration. User interaction with the system is used to receive user-defined requirements and view configuration feedback.

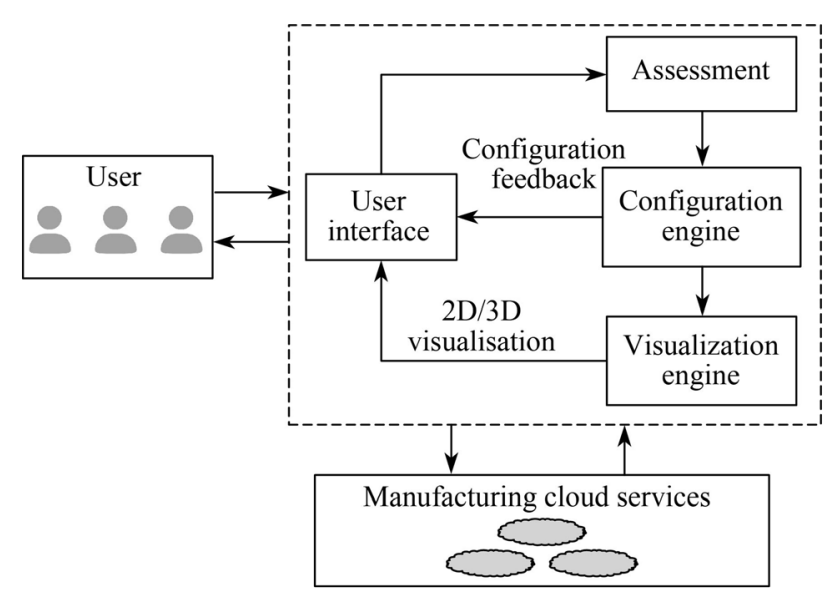

Fig. 7 Relationship between product configuration and manufacturing cloud services

\subsection{Key technologies of product collaborative design}

\subsubsection{Dynamic monitoring technology}

The product platform for cloud manufacturing is a dynamic service system. Dynamic monitoring is an essential function to ensure the efficient completion of platform services [30]. The dynamic monitoring of the product design platform for cloud manufacturing includes three aspects: collaborative process monitoring, dynamic resource monitoring, and system fault monitoring.

(i) Collaborative process monitoring. In the cloud manufacturing environment, conflicting behaviors are detected at each coordinated stage. An intelligent conflict-detection model for the cloud manufacturing service model is established to effectively monitor various conflicts in the design process and ensure that the design tasks are completed efficiently.

(ii) Dynamic resource monitoring. This is mainly used to build an extensible resource monitoring framework that meets the needs of different types of resources, and to study flexible and efficient resource monitoring strategies. The dynamic monitoring of resources facilitates the reduction of resource monitoring costs and the timely detection and diagnosis of resource failures.

(iii) System fault monitoring. By establishing a multilevel monitoring mechanism, the system can automatically predict and eliminate certain emergencies such as network communication failures and the sudden exits of designers. Faults are eliminated in a timely manner through corresponding fault tolerance, migration, and recovery strategies to ensure uninterrupted operation of the system.

\subsubsection{System security technology}

The product platform for cloud manufacturing has a high degree of openness, which means that system security issues are crucial. During the operation of the platform, it is necessary to ensure that the task is completed efficiently, but also to avoid the leakage of user data and design data. At the same time, it is also necessary to prevent attacks from various types of Trojan horses.

Therefore, the system security technology mainly solves the following problems. Firstly, the number of users on the platform is huge, and users are dynamically added and deleted during the task. This is a test of the security of the platform. Secondly, in the task coordination process, on the one hand, it is necessary to grant the user the minimum 
authority required to complete the tasks, but also to avoid excessive authorization. On the other hand, data consistency must be guaranteed during the entire task execution process.

\section{Case study and discussion}

\subsection{Overview of structure}

A good product design model can increase the efficiency and quality, and decrease the cost and time of the entire product manufacturing process. This is important as product and production demand changes rapidly in today's market [31]. The following is a case study of a product design system for cloud manufacturing that delivers outstanding performance throughout the product life cycle.

Figure 8 shows that IaaS, PaaS, and SaaS still provide important services for this product platform for cloud manufacturing. The storage, sensor, and other capabilities are provided as a service in IaaS. Various platforms are provided in PaaS. SaaS is a cloud computing service. The application example is a product platform for cloud manufacturing. Cloud computing is the key technology to support the product platform for cloud manufacturing. SaaS provides service in which the software runs on the cloud, and there is no need to install the application on the client computer [20].
The new concept of "MaaS" is a service through the entire life cycle of argumentation, design, fabrication, experiment, simulation, and integration. This application example is a public cloud manufacturing service platform. It is characterized as being available from a third-party service provider, and is used to realize the sharing and optimal allocation of all manufacturing resources and capabilities owned by different enterprises and organizations, especially for small- and medium-sized enterprises (SMEs).

Based on the research of the product platform architecture proposed in Sect. 2 of this paper, the system is constructed according to the actual business situation of the enterprise, and its structure is shown in Fig. 8.

\subsection{System functions}

Based on the proposed framework and key technologies, a cloud-based product platform was developed for a company. The home page of the platform is shown in Fig. 9. The product platform currently provides five main services: user data management service, product management service, resources management service, conflict resolution service, and system security service.

The user data management service refers to the authorization and management of user rights. This is achieved by the user's role assignment. Different roles are granted different levels of authority. For example, product
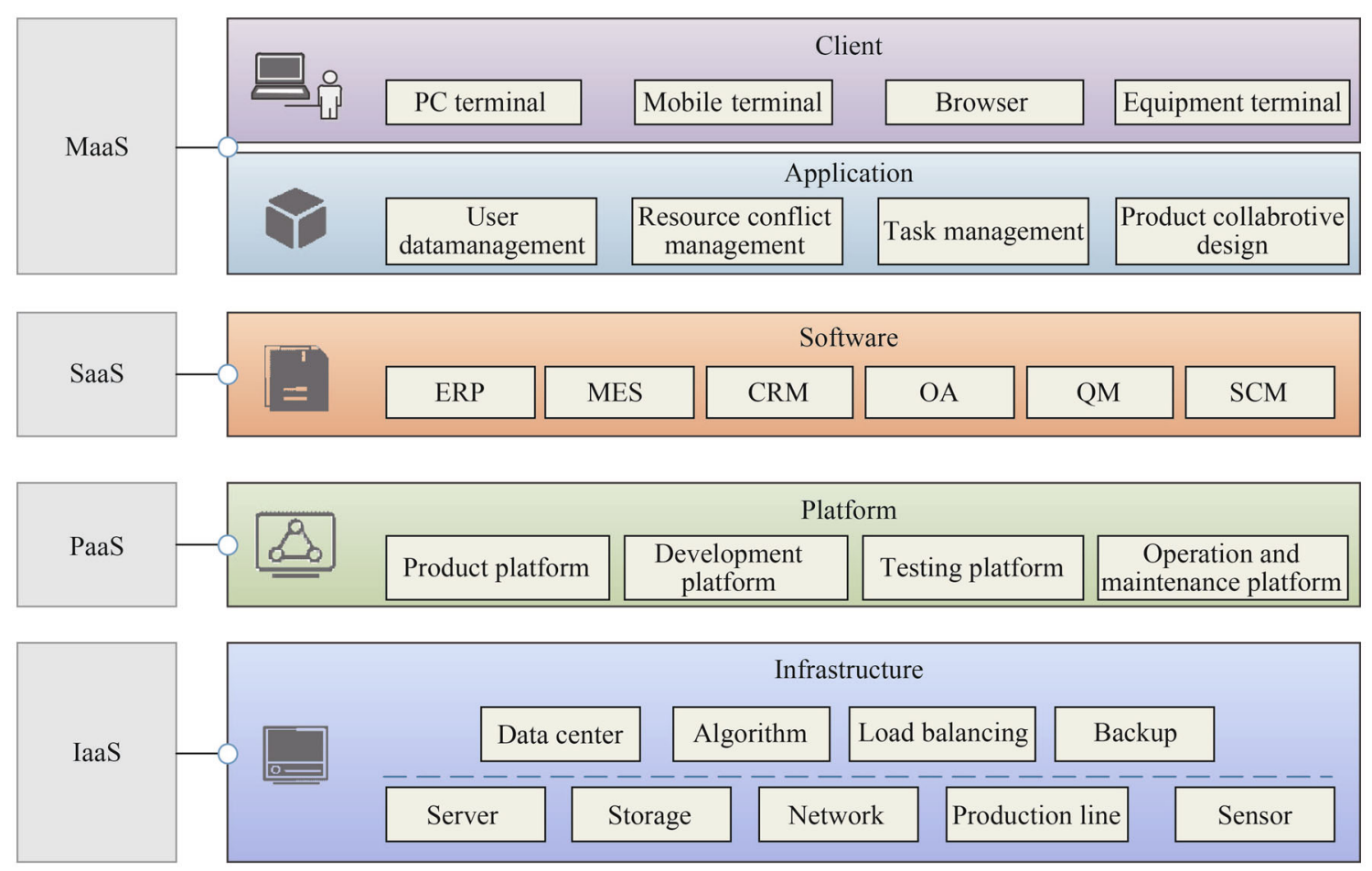

Fig. 8 Actual architecture of the product platform for cloud manufacturing 
designers' rights are limited to product codesign applications, while product managers have full rights in product management services. Different roles interact through the information-sharing module within the platform. This service uses existing manufacturing information technologies to realize data management. System security technology is also used to ensure data security.

The product management service works in the product lifecycle management, including codesign, comodeling, cosimulation, and comanufacturing. This service was primarily developed by module division, product platform parameterized design, and product configuration technologies to realize efficient product life cycle management. The resource management services are used to describe, encapsulate, manage, and apply resources, which enables users to utilize resources quickly and efficiently. The implementation of this service needs IoT technology to intelligently sense physical resources and connect to the wider internet.

In addition, unified classification and description of resources technology are used to facilitate the integration, sharing, and management of manufacturing resources. Virtualization of resource technology is used to virtual manufacturing resources and encapsulate them into services. The conflict resolution service mainly provides applications such as detection and classification, the formulation of resolution strategies, resolution of task allocation, and intelligent processing for conflicts generated during system operation. The system security service is applied to dynamically monitor all parameters of the system during the operation process to ensure the security of various data in the platform and to prevent attacks of various types of Trojans or viruses. The services of conflict resolution and system security use dynamic monitoring technology to monitor the collaborative process and

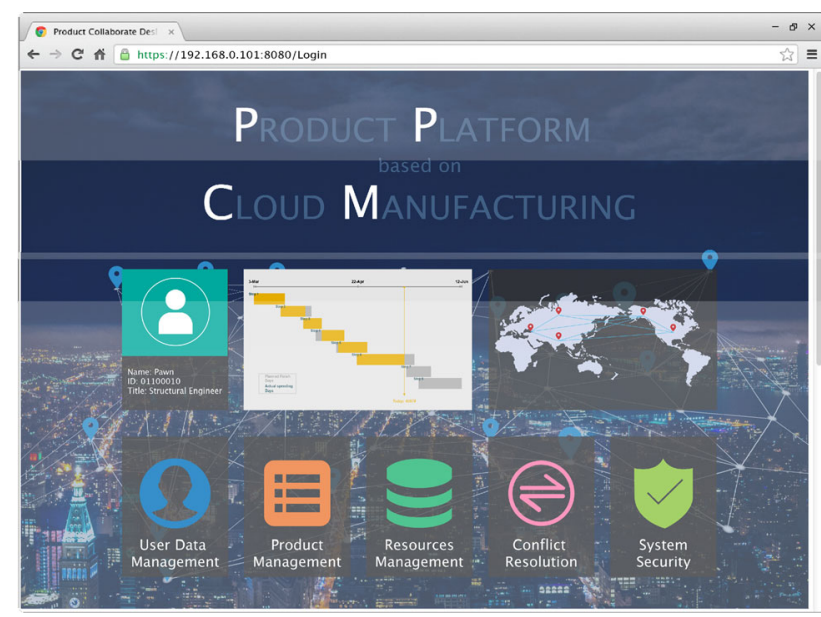

Fig. 9 Home page of product platform for cloud manufacturing dynamic resources to eliminate system and internet faults and recover the system in a timely manner.

This section focuses on the product management service prototype of the product platform for cloud manufacturing. A CNC milling machine is taken as an example to illustrate the applications of product codesign, product comodeling, and product cosimulation.

The interface of the product collaborative design application is shown in Fig. 10. This page shows the 3D structure and the $2 \mathrm{D}$ engineering drawings of the CNC milling machine, as well as information about the model files. Click the "Open model" button to operate the Pro/ ENGINEER interface and read the 3D structure and 2D drawings of the selected structure. After manually editing, click the "Save model" button to save it in the corresponding model database. Click the "Read data" button to read the relevant parameters of the 3D model, and then modify the structural model through the parameter-driven method. Finally, click the "Update database" and "Refresh" buttons. The system will automatically modify the size parameters of the 3D model. This process realizes the parametric customization of the product.

The interface of the product collaborative modeling application is shown in Fig. 11. Firstly, according to a demand analysis of users, the series of CNC milling machines are determined. The parameter, structural, and auxiliary structure characteristics in each module of the CNC miller are determined, and different structural module codes are selected. Then, the modules are combined and selected to quickly design new $\mathrm{CNC}$ milling products. Finally, the main structural module of the CNC miller is modified and saved, and the assembly of the structural modules forms a CNC milling machine.

The interface of the product collaborative simulation application is shown in Fig. 12. Importing the model of the CNC milling machine, applying loads and constraints, and

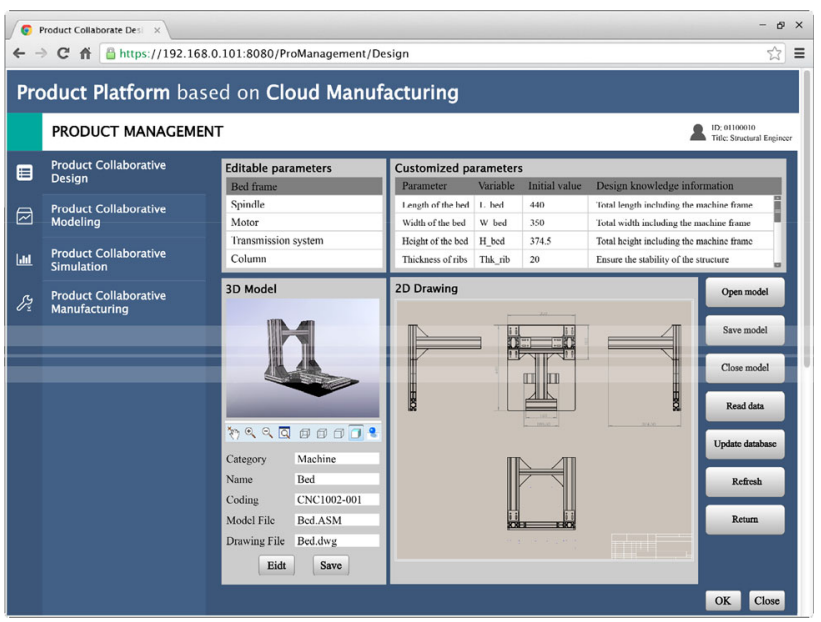

Fig. 10 Interface of product collaborative design 


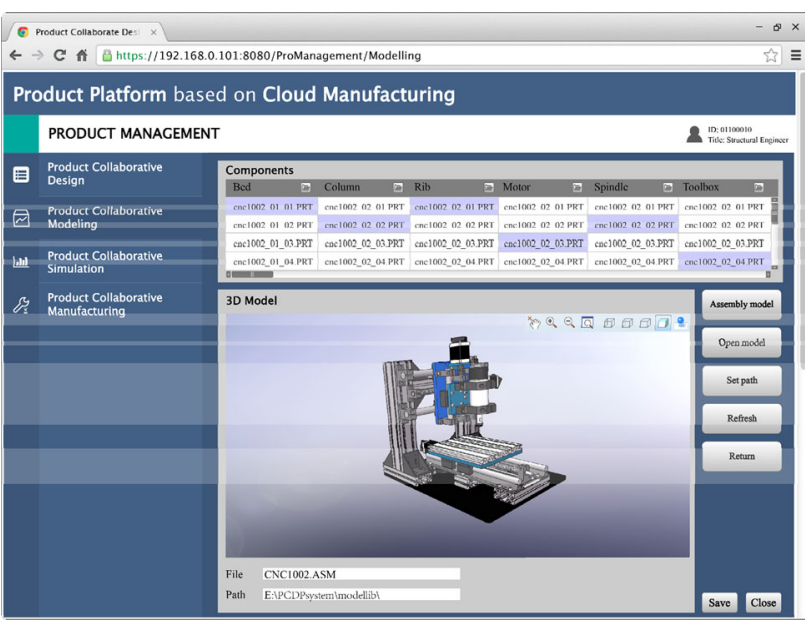

Fig. 11 Page of collaboration modeling in the product platform for cloud manufacturing

postprocessing can all be achieved through the command flow. The task number, task name, and other information can be edited by the user. At the same time, the end time of the task can be set. The system will dynamically call related resources based on the end time, such as the number of CPUs used by the server in the calculation process, to ensure that the task is completed on time. When the task is completed, the results of the simulation analysis are displayed on the interface. The meshing results of the CNC milling machine and the static analysis results are shown in Fig. 12. The analysis results can be output as HTML files.

\subsection{Comparison and analysis}

In this study, the task assignation time and task completion time are used as indicators to measure the efficiency of the traditional manufacturing model and the efficiency of the

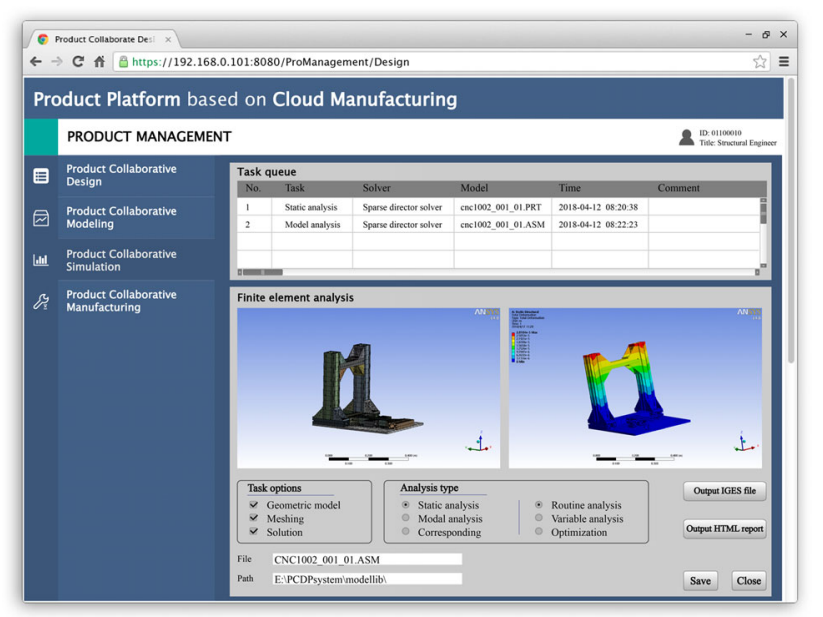

Fig. 12 Collaboration simulation page of the product platform for cloud manufacturing
Table 2 Time required for A, B, and C to assign tasks

\begin{tabular}{lllrrrl}
\hline Company & \multicolumn{6}{l}{ Time to assign tasks } \\
\cline { 2 - 7 } & $10^{1}$ & $10^{2}$ & $10^{3}$ & $10^{4}$ & $10^{5}$ & $10^{6}$ \\
\hline $\mathrm{At}$ & 4.5 & 7.5 & 12 & 14 & 16 & 20 \\
$\mathrm{Ac}$ & 5 & 6 & 8 & 9 & 11 & 12 \\
$\mathrm{Bt}$ & 3 & 7 & 11 & 12 & 18 & 22.5 \\
$\mathrm{Bc}$ & 4 & 5.5 & 8 & 9 & 10 & 12.5 \\
$\mathrm{Ct}$ & 4.5 & 7 & 10 & 13 & 17 & 22 \\
$\mathrm{Cc}$ & 4 & 6 & 7 & 8 & 10 & 12 \\
\hline
\end{tabular}

cloud manufacturing model. Three manufacturing companies $\mathrm{A}, \mathrm{B}$, and $\mathrm{C}$ located in Beijing that used this system were selected as research objects. With permission, the research team entered the MES systems and databases of these companies, and the relevant data of $\mathrm{A}, \mathrm{B}$, and $\mathrm{C}$ before and after applying the system were collected.

The data are listed in Tables 2 and 3. At means that Company $\mathrm{A}$ is in the traditional manufacturing mode; Ac means that Company $\mathrm{A}$ is in the cloud manufacturing mode, and so on. The average value of the three companies' mission times is used as an evaluation basis. Because the amount of data is too large, the key node data are selected to draw a chart to compare the two manufacturing modes.

The processed data are plotted as a graph shown in Fig. 13. The scatter in the first part is the average of the three companies' mission times, and the curve is fitted by scatter coordinates. The graph in the second part shows the difference in time required for an enterprise to assign a task in two manufacturing modes. In the initial stage, owing to the complex operating mechanism of cloud manufacturing, the response speed is not as good as that of traditional manufacturing. When the amount of tasks reaches a certain value, the computational advantage of the cloud manufacturing is observed.

Table 3 Time required for A, B, and C to complete tasks

\begin{tabular}{lcccccc}
\hline Company & \multicolumn{7}{l}{ Time to complete tasks } \\
\cline { 2 - 7 } & $10^{1}$ & $10^{2}$ & $10^{3}$ & $10^{4}$ & $10^{5}$ & $10^{6}$ \\
\hline At & 10 & 14 & 24 & 38 & 48 & 62 \\
Ac & 14 & 15 & 18 & 23 & 32 & 42 \\
Bt & 8 & 13 & 20 & 35 & 48 & 63 \\
Bc & 13 & 15 & 19 & 24 & 30.5 & 38 \\
Ct & 10 & 14 & 22 & 36 & 46 & 60 \\
Cc & 12 & 16 & 18 & 22 & 31 & 39 \\
\hline
\end{tabular}




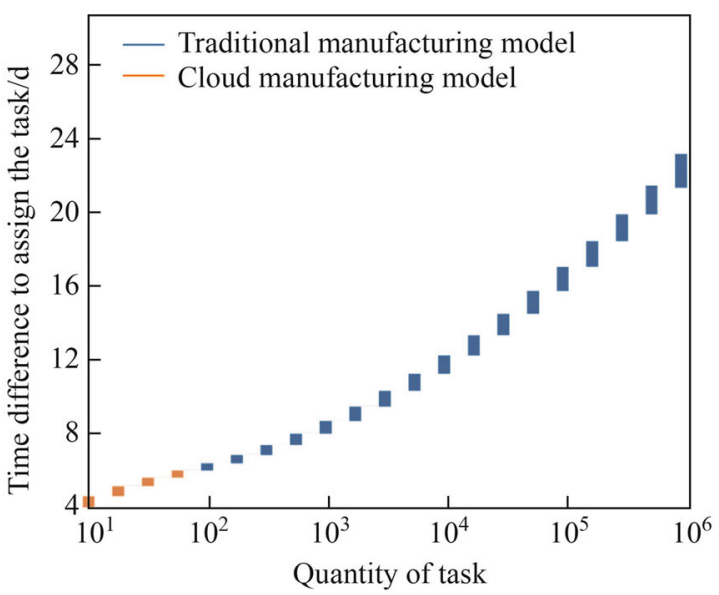

(a)

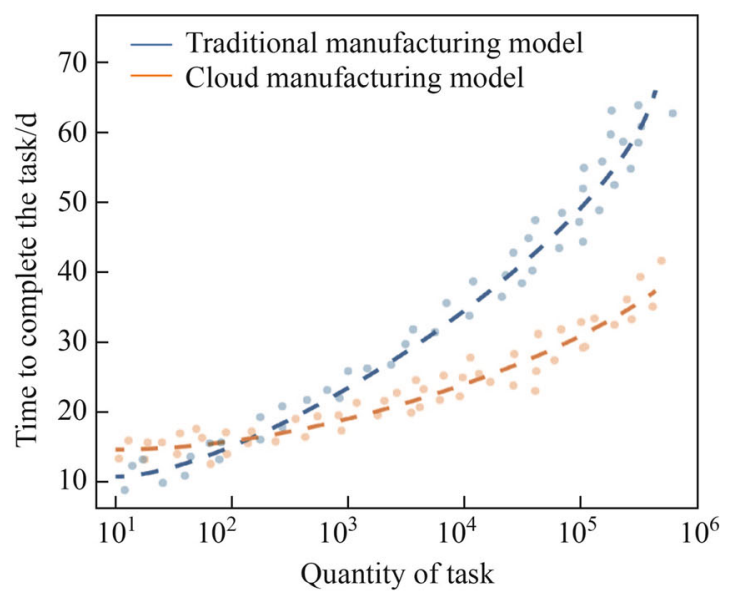

(b)

Fig. 13 Differences of time to assign and complete the task based on two manufacturing modes

\section{Conclusions}

In this study, a product platform model based on cloud manufacturing was considered more suitable for current market development needs. On this basis, a product platform architecture for cloud manufacturing was proposed, and the key technologies involved in platform construction were discussed and analyzed. The product platform for cloud manufacturing proposed in this paper is fused and expanded to the traditional product platform, and it supports business collaboration between distributed enterprises, which share standardized design, manufacturing, information, and technology resources related to product development. Based on the research, a system prototype of the product platform for cloud manufacturing, deployed by a company in Beijing, was applied to illustrate the theory proposed in this paper. This was described as a relevant example of cloud manufacturing. Potential topics for future study include comparing the effectiveness of different cloud manufacturing architectures and improving the system functions of the product platform based on cloud manufacturing to support 3D printing and big data analysis [32].

Acknowledgements This research was supported by the National Key Research and Development Program of China (Grant No. 2017YFB1104201), the National Natural Science Foundation of China (Grant No. 51675028), the Aeronautical Science Foundation of China (Grant No. 20171651015), and the State Key Lab of Digital Manufacturing Equipment \& Technology (Grant No. DMETKF2017020).

Open Access This article is licensed under a Creative Commons Attribution 4.0 International License, which permits use, sharing, adaptation, distribution and reproduction in any medium or format, as long as you give appropriate credit to the original author(s) and the source, provide a link to the Creative Commons licence, and indicate if changes were made. The images or other third party material in this article are included in the article's Creative Commons licence, unless indicated otherwise in a credit line to the material. If material is not included in the article's Creative Commons licence and your intended use is not permitted by statutory regulation or exceeds the permitted use, you will need to obtain permission directly from the copyright holder. To view a copy of this licence, visit http://creativecommons. org/licenses/by/4.0/.

\section{References}

1. Li BH, Lin Z, Lei R et al (2011) Further discussion on cloud manufacturing. Comput Integr Manuf Syst 17(3):449-457

2. Li B, Zhang L, Chai X (2010) Introduction to cloud manufacturing. ZTE. Communications 8(4):6-9

3. Golightly D, Sharples S, Patel H et al (2016) Manufacturing in the cloud: a human factors perspective. Int J Ind Ergon 55:12-21

4. He W, Xu L (2015) A state-of-the-art survey of cloud manufacturing. Int J Comput Integr Manuf 28(3):239-250

5. Jiang YX, Zhang Y, Ma JW (2013) Research on virtualization of manufacturing resources. In: Proceedings of 2013 2nd international conference on measurement, information and control, vol 2, pp 1060-1064. IEEE

6. Ren L, Cui J, Li N et al (2015) Cloud-based intelligent user interface for cloud manufacturing: model, technology, and application. J Manuf Sci Eng 137(4):040910

7. Ma CX, Ren L, Teng DX et al (2011) Ubiquitous human-computer interaction in cloud manufacturing. Comput Integr Manuf Syst 17(3):504-510

8. Wei Y, Blake MB (2010) Service-oriented computing and cloud computing: challenges and opportunities. IEEE Internet Comput 14(6):72-75

9. Singh B, Dhawan S, Arora A et al (2013) A view of cloud computing. Int J Comput Technol 4(2b1):50-58

10. Ding B, Yu XY, Sun LJ (2012) A cloud-based collaborative manufacturing resource sharing services. Inf Technol $J$ 11(9):1258-1264

11. Ren L, Zhang L, Wang L et al (2017) Cloud manufacturing: key characteristics and applications. Int $\mathrm{J}$ Comput Integr Manuf 30(6):501-515

12. Katzmaier A, Hanneghan M (2013) Design pattern evaluation of mobile and web based application frameworks. In: International 
conference on developments in esystems engineering, pp 157-162. IEEE Computer Society

13. Zhang L, Luo YL, Fan WH et al (2011) Analyses of cloud manufacturing and related advanced manufacturing models. Comput Integr Manuf Syst 17(3):458-468

14. Fei T, Lin Z, Hua G et al (2011) Typical characteristics of cloud manufacturing and several key issues of cloud service composition. Comput Integr Manuf Syst 17(3):477-486

15. Yin C, Huang BQ, Liu F et al (2011) Common key technology system of cloud manufacturing service platform for small and medium enterprises. Comput Integr Manuf Syst 17(3):495-503

16. Gu P, Hashemian M, Nee AYC (2004) Adaptable design. CIRP Ann Manuf Technol 53(2):539-557

17. Tao F, Laili YJ, Xu LD et al (2013) FC-PACO-RM: a parallel method for service composition optimal-selection in cloud manufacturing system. IEEE Trans Ind Inf 9(4):2023-2033

18. Xu X (2012) From cloud computing to cloud manufacturing. Robot Comput Integr Manuf 28(1):75-86

19. Ren L, Zhang L, Zhang YB et al (2011) Resource virtualization in cloud manufacturing. Comput Integr Manuf Syst 17(3):511-518

20. Wang W, Liu F (2012) The research of cloud manufacturing resource discovery mechanism. In: 2012 7th international conference on computer science \& education (ICCSE), pp 188-191. IEEE

21. Tao F, Zhang L, Venkatesh VC et al (2011) Cloud manufacturing: a computing and service-oriented manufacturing model. J Eng Manuf 225(10):1969-1976

22. Tao F, Zuo Y, Xu LD et al (2014) IoT-based intelligent perception and access of manufacturing resource toward cloud manufacturing. IEEE Trans Ind Inf 10(2):1547-1557

23. Burkett WC (2001) Product data markup language: a new paradigm for product data exchange and integration. Comput Aided Des 33(7):489-500

24. Srinivasan N, Paolucci M, Sycara K (2006) Semantic web service discovery in the OWL-S IDE. In: Proceedings of the 39th annual Hawaii international conference on system sciences (HICSS'06), vol 6, pp 109b-109b. IEEE

25. Felfernig A, Friedrich GE, Jannach D (2000) UML as domain specific language for the construction of knowledge-based configuration systems. Int J Softw Eng Knowl Eng 10(4):449-469

26. Liu N, Li X, Wang Q (2011) A resource and capability virtualization method for cloud manufacturing systems. In: 2011 IEEE international conference on systems, man, and cybernetics, pp 1003-1008. IEEE

27. Wei W, Liang H, Xu SP (2015) Module division method of robust product platform based on improved artificial immune algorithms. Comput Integr Manuf Syst 21(4):885-893

28. Shuping YI, Tan M, Guo Z et al (2015) Manufacturing task decomposition optimization in cloud manufacturing service platform. Comput Integr Manuf Syst 21(8):2201-2212

29. Yip AL, Corney JR, Jagadeesan AP et al (2013) A product configurator for cloud manufacturing. In: ASME 2013 international manufacturing science and engineering conference collocated with the 41st North American manufacturing research conference, June 10-14, Madison, Wisconsin, USA

30. Li BH, Zhang L, Wang SL et al (2010) Cloud manufacturing: a new service-oriented networked manufacturing model. Comput Integr Manuf Syst 16(1):1-7
31. Wang L, Keshavarzmanesh S, Feng HY et al (2009) Assembly process planning and its future in collaborative manufacturing: a review. Int J Adv Manuf Technol 41(1/2):132-144

32. Wei W, Liang PF (2018) A product platform architecture for cloud manufacturing. In: Proceedings of 2018 48th international conference on computers and industrial engineering, Auckland, New Zealand Afghah

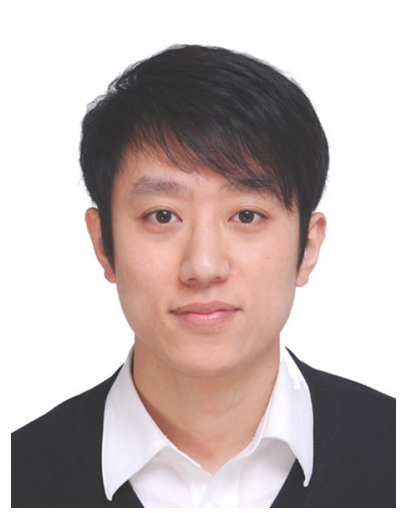

Wei Wei, Associate Professor, School of Mechanical Engineering and Automation, Beihang University. Major research fields include product developmentengineering, intelligent manufacturing, product life cycle management, virtual reality and augmented reality technology, and machine vision technology.

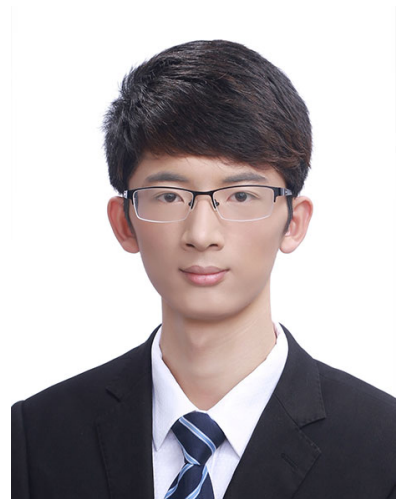

Feng Zhou , Master Student, School of Mechanical Engineering and Automation, Beihang University. Major research fields include product development engineering, intelligent manufacturing.

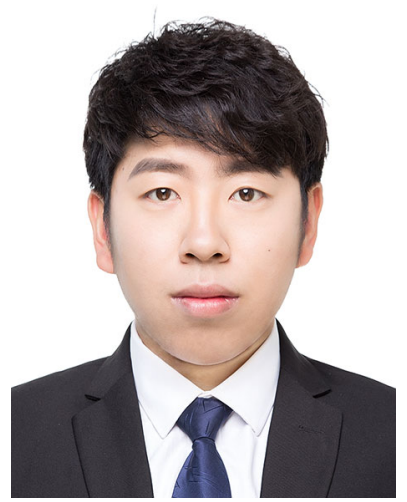

Peng-Fei Liang, Master Student, School of Mechanical Engineering and Automation, Beihang University. Major research fields include product development engineering, intelligent manufacturing. 